\title{
Composite Coatings Are Formed by Complex Methods
}

\author{
Andrew E. Stetsko \\ Department of Computer Engineering Printing, Ukraine Academy of Printing, Ukraine
}

Copyright $(2016$ by authors, all rights reserved. Authors agree that this article remains permanently open access under the terms of the Creative Commons Attribution License 4.0 International License

\begin{abstract}
Retrieved surface layer, which is fine-dyspersated carbide composite structure area which has a higher microhardness and sufficient ductility. It is used for parts that are in friction pairs under conditions of dynamic loads. Some parts that require high resource work, reinforcing coating applied to high thickness $-300 \mu \mathrm{m}$. Such details can be processed several times during their gradual deterioration. Work surface heavily loaded parts operating at high unit pressures are applied coating reinforced, composite zone, there is a high content of chromium carbides and large microhardness. The presence of $\mathrm{Ni}$ content in the homogeneous zone positively influences the work of such details.
\end{abstract}

Keywords Diffusion, Chemical Heat Treatment, Methods of Chemical and Thermal Processing, Microhardness

\section{Introduction}

Synthesis methods and techniques for strengthening of the working surfaces of machine parts with new qualitative and quantitative characteristics are the promising areas of strengthening the development of modern technologies [1].

Chemical heat treatment is one of the most effective methods of influencing the conjugated surfaces of machine parts [2], [3]. There are diffusion layers of high quality after its implementation at operational surfaces, which then pass to the core material, which is positive in terms of strength and stability. Methods of chemical and thermal processing (CTP) are also a technology, engineering and service company with trained professionals and experience of existing equipment.

Diffusion carbide coating is an effective means of protecting metals and alloys from corrosion corrosive environments. Promising is the use of complex carbide coatings when combining the positive properties of one-component coatings must have higher protective properties.

Nevertheless, CTP restricts the use of physical and mechanical properties of the material.
Objective: to develop a new method of surface hardening, providing the required quality characteristics of machine parts and tools.

\section{Materials and Methods}

In the literature, there are several ways of combining CTP that can run as alternately and simultaneously. This approach to the use of CTP methods, and the type and processing mode enables hardened surface layers desired characteristics.

A combination of two or more ways to CTP for hardness of surface machine parts perspective. Those are methods of chemical and thermal processing. This complex treatment in combination with certain modes enables diffusion of hardened surface layers. This one is considerable hardness and low brittleness and works well in harsh operating conditions. The use of several methods of technological impact on the processing surface allows you to choose the best modes to provide benefits above named methods. In the literature a combination of several methods of chemical and thermal processing is found and it may be performed alternately as well as simultaneously. Such use of CTP methods, and the type and processing mode enables hardened surface layers with desired characteristics.

Researchers used the strengthening of machine parts and tools, methods of chemical treatment saturation of the surface layers of two or more components such positive note properties, they have become objects of strengthening.

Most scientists pointed to the simultaneous acquisition of properties of high hardness and ductility, which is unattainable in one-component diffusion saturation. Diffusion processes in systems $\mathrm{Ti}, \mathrm{Cr}, \mathrm{Al}$ and other elements involved leading scientists [4], [5], [6], [7] of the world's.

Valuable physical and mechanical characteristics are achieved by the formation of hardened surface layers with defined morphology. If chemical-thermal saturation of two or more controls diffusion quantitative content elements, modes of processing and the choice of the basic material parts can achieve the desired characteristics of much broader range than the traditional chemical and thermal processing one-component saturation. Besides, the determined one is processing which does not exclude CTP along with other 
methods of technological impact on the surface of the workpiece, both before and after the process of diffusion. This substantially expands the scope of this method for a variety of (wide range) of machine parts which operate in different environments with different loading-speed characteristics.

Particularly valuable (perspective) way CTP is compatible diffusive surface saturation chromium and titanium, which will get reinforced layers as high hardness and corrosion.

This research is carried out to provide plasticity to the CTP process which should carry out $\mathrm{Ni}-\mathrm{Co}-\mathrm{P}$ chemical deposition, providing consolidated presence in the surface layer of nickel. It also increases and the strength and ductility, and the presence of phosphorus act as soluble solid strengthener, competitive on manganese and silicon. Chemical deposition also significantly affects the morphology of the obtained hardened layers, especially can achieve their composite structure of considerable thickness. This strengthened complex treatment is optimal for parts operating under severe conditions of friction in aggressive environments to ensure their maximum life.

The proposed complex method of consolidation applied for workpieces made of steel 45 . The method includes the following steps:

- previous machining the workpiece;

- preparation for chemical coating;

- the application of chemical coatings (several formulations);

- preparation for chemical and heat treatment;

- isothermal aging $\left(1\right.$ hour at $\left.800^{\circ} \mathrm{C}\right)$;

- conducting chemical-thermal treatment $(7 \mathrm{hr}$. at $\left.1100^{\circ} \mathrm{C}\right)$;

- cleaning of workpiece;

- the final machining of the workpiece;

- control operation is finished part.

Dry deposition was carried out in aqueous solution with density downloads $41 / \mathrm{dm}^{2}$, which is higher than industrial, but has reduced the deposition time from 120 to 60 minutes at a temperature of $80-95^{\circ} \mathrm{C}$ deposition and supported solution $\mathrm{pH}$ at 9-10 [8], [9], [10], [11].

Diffusion $\mathrm{Cr}-\mathrm{Ti}$ is conducted in retort with fusible shutter for 7 hours powder mixtures, wt.\%: ferrochrome -40 , ferrotitanium -20 , alumina -33 , ammonium chloride -7 .

Hours isothermal exposure [12] was carried out during the heating at a temperature of $800^{\circ} \mathrm{C}$.

As a result of this treatment, the surfaces of workpieces formed strengthening reinforced diffusion layers (Fig. 1), which included multiplied zones.

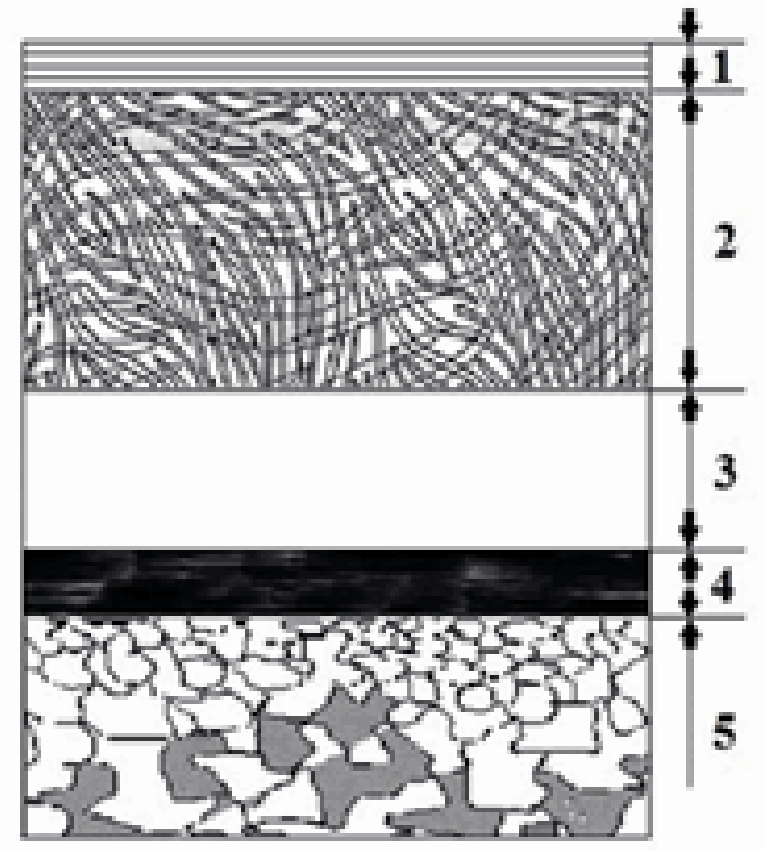

Figure 1. The structure of the diffusion layer after diffusion saturation $\mathrm{Cr}$ and Ti: 1 - titanium carbides; 2 - titanium and chromium carbides in solid solution $\mathrm{Cr}$ and $\mathrm{Ti}$ in $\alpha$-Fe; 3 - solid solution $\mathrm{Cr}$ and $\mathrm{Ti}$ in $\alpha$-Fe; 4 - eutectoid layer; 5 - without carbon layer.

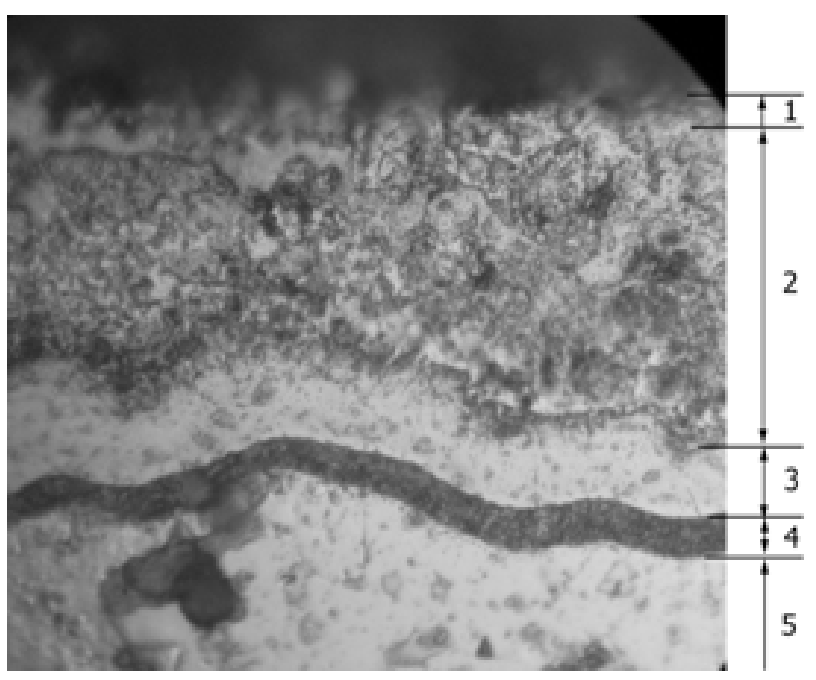

Figure 2. The microstructure of hardened diffusion layer of chemically Ni-Co-P coating for recipe №1 and for the diffusion $\mathrm{Cr}$-Ti modes: isothermal holding 1 hour. at $800^{\circ} \mathrm{C}$, diffusive saturation $\mathrm{Cr}$ - $\mathrm{Ti} 7$ hours at a temperature of $1100^{\circ} \mathrm{C}$; magnification $600^{\mathrm{x}}$

Depending on the formulation of chemical coatings, strengthened diffusion layers of different morphology obtained the values of physical and mechanical characteristics. 


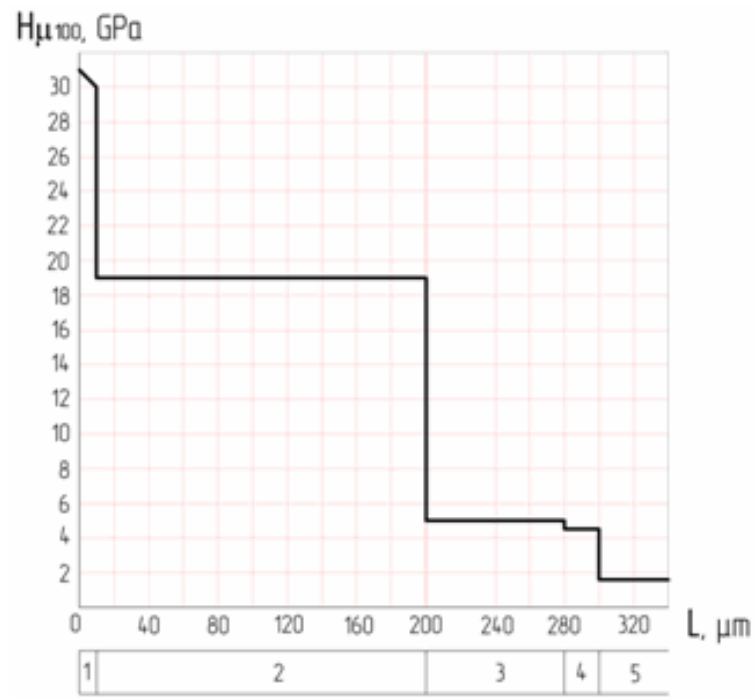

Figure 3. The microhardness averaged diffusion hardened layer of chemically Ni-Co-P coating for recipe №1 and for the diffusion of $\mathrm{Cr}-\mathrm{Ti}$ modes: isothermal holding 1 hour at $800^{\circ} \mathrm{C}$, diffusive saturation $\mathrm{Cr}-\mathrm{Ti} 7$ hours at a temperature of $1100^{\circ} \mathrm{C}$

Foreign zone 1 titanium carbides (Fig. 2, 4, 6, 8, 10) has a small thickness (5 to 10 microns) obtained for all types of reinforced layers. This zone has high performance microhardness up to $35 \mathrm{GPa}$ (Fig. 3, 5, 7, 9, 11). Because of its high hardness and hence brittleness and small thickness should not be regarded as working, especially for parts and cutting tools, working under dynamic loads. Due to its high hardness, its wear resistance has high rates, when deals with non-rigid modes.

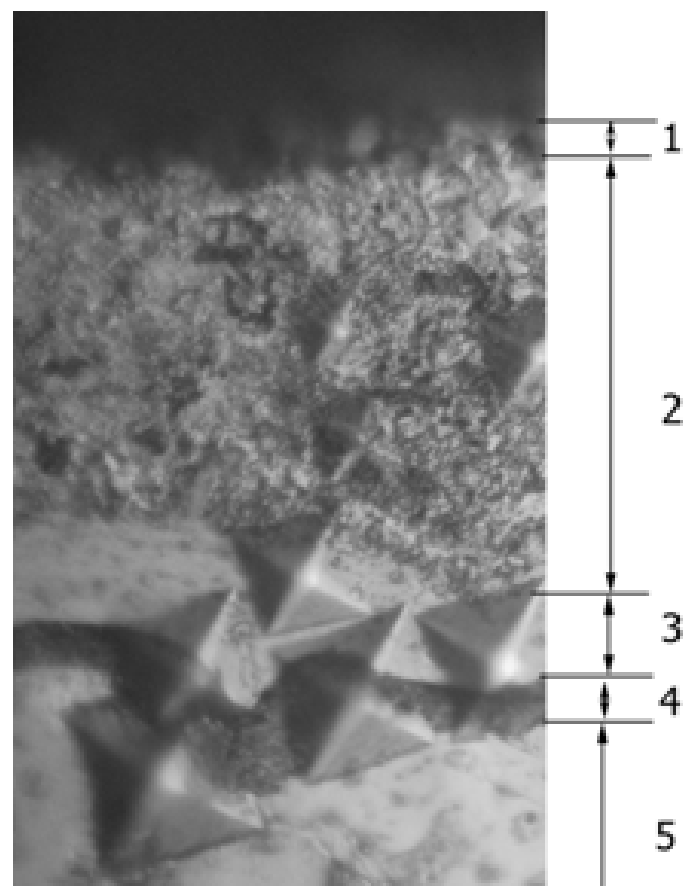

Figure 4. The microstructure of hardened diffusion layer of chemically Ni-Co-P coating for recipe №2 and diffusion Cr-Ti regimes: isothermal holding 1 hour at $800^{\circ} \mathrm{C}$, diffusive saturation $\mathrm{Cr}$ - $\mathrm{Ti} 7$ hours at a temperature of $1100^{\circ} \mathrm{C}$; magnification $600^{\mathrm{x}}$

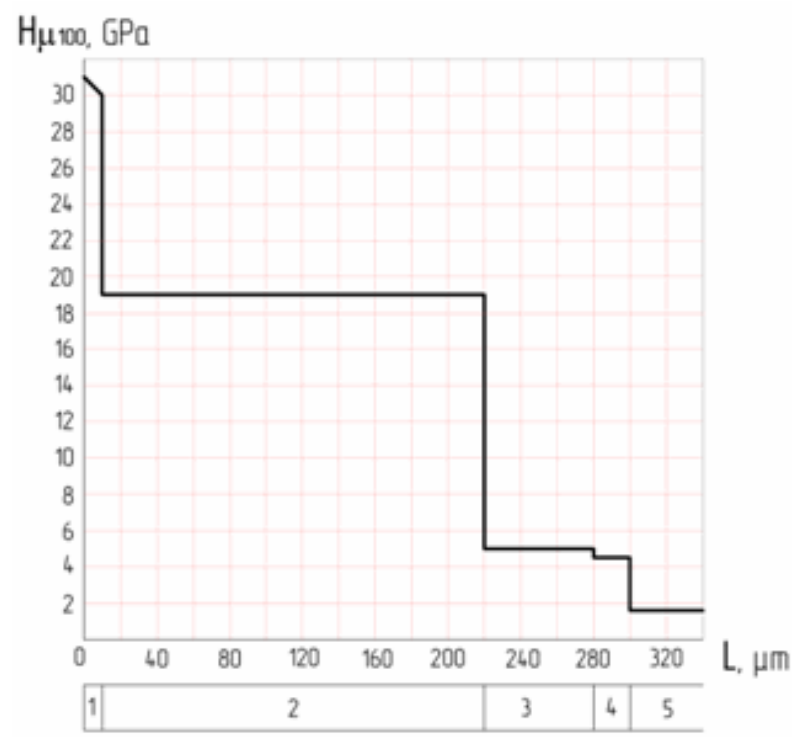

Figure 5. The microhardness averaged diffusion hardened layer of chemically Ni-Co-P coating for recipe №2 and diffusion $\mathrm{Cr}$-Ti regimes: isothermal holding 1 hour at $800^{\circ} \mathrm{C}$, diffusive saturation $\mathrm{Cr}$-Ti 7 hours at a temperature of $1100^{\circ} \mathrm{C}$

Zone 2 composite carbides of chromium and titanium in the solid solution chromium and titanium in $\alpha$-iron has a thickness of 200 microns and above, not microhardness averaged below $20 \mathrm{GPa}$. Such physical and mechanical characteristics allow fortifications detail with the data layers to get high performance durability. Carbide component of the layer can stand with high specific pressure. And due to its plasticity solid solution will "relax" Accumulating tensions periodically reducing their value.

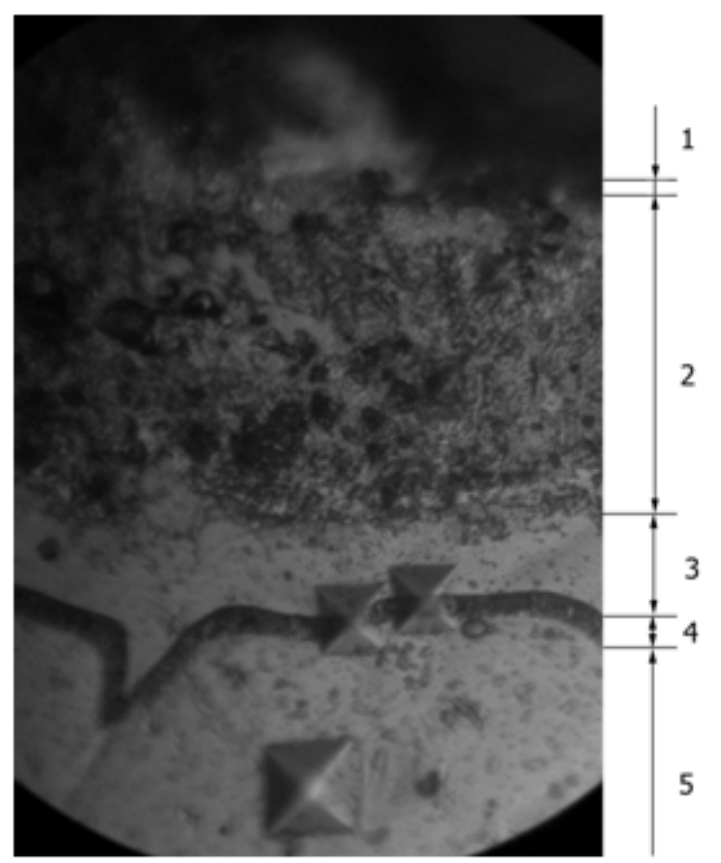

Figure 6. The microstructure of hardened diffusion layer of chemically Ni-Co-P coating for recipe №3 and diffusion Cr-Ti regimes: isothermal holding 1 hour at $800^{\circ} \mathrm{C}$, diffusive saturation $\mathrm{Cr}-\mathrm{Ti} 7$ hours at a temperature of $1100^{\circ} \mathrm{C}$; magnification $600^{\mathrm{x}}$ 


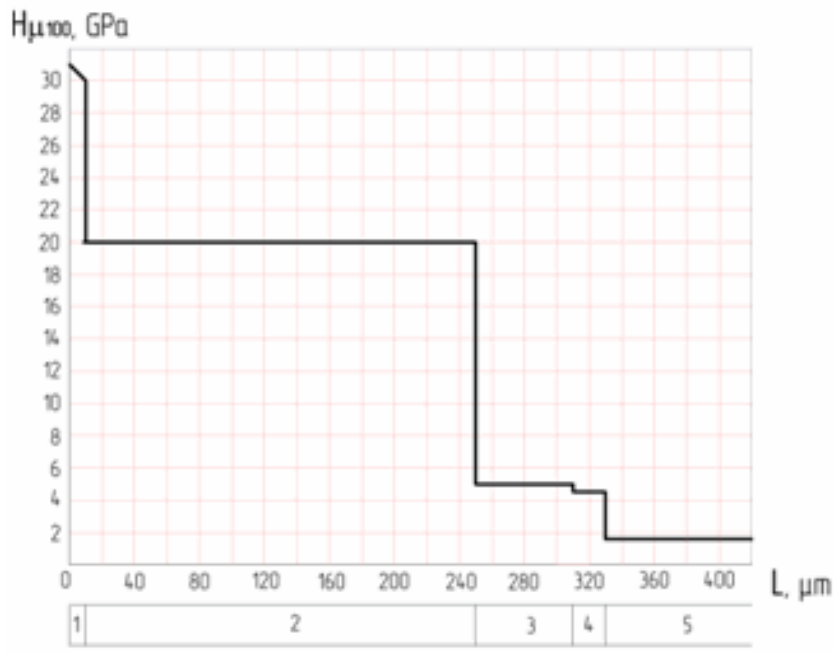

Figure 7. The microhardness averaged diffusion hardened layer of chemically Ni-Co-P coating for recipe №3 and diffusion Cr-Ti regimes: isothermal holding 1 hour at $800^{\circ} \mathrm{C}$, diffusive saturation $\mathrm{Cr}-\mathrm{Ti} 7$ hours at a temperature of $1100^{\circ} \mathrm{C}$

Some hardened layers (Fig. 8) may have pores in zone 2 of carbides of chromium and titanium in the solid solution chromium and titanium in $\alpha$-iron. This structure allows the diffusion layer to collect food deterioration during a pore formed in the ground holes. It will no longer fall into the zone of contact and accelerate the process of deterioration.

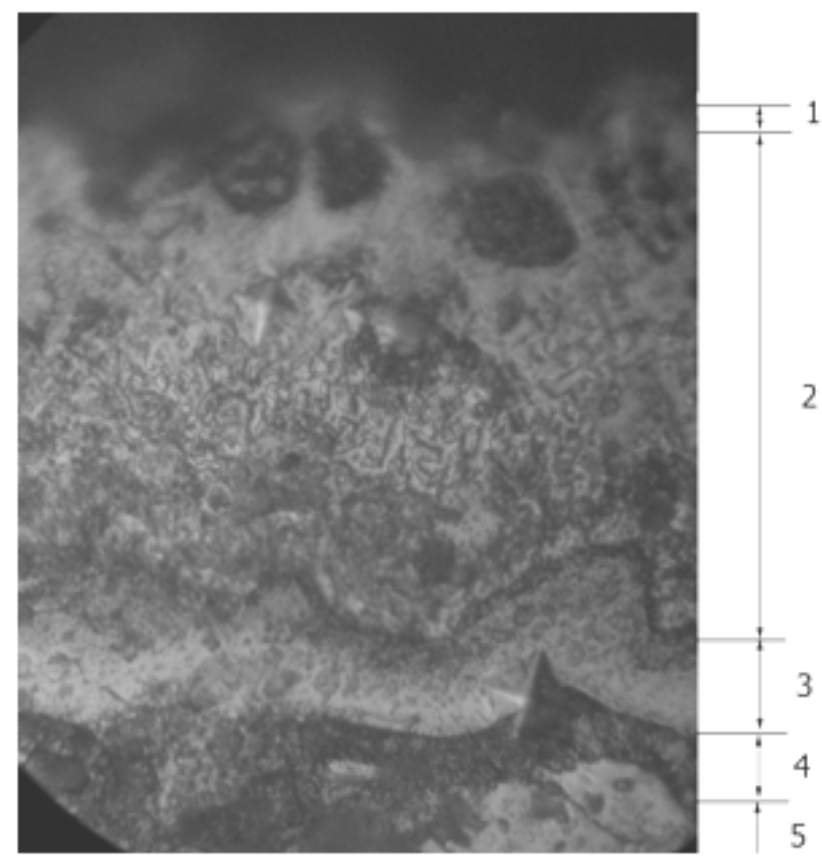

Figure 8. The microstructure of hardened diffusion layer of chemically Ni-Co-P coating for recipe №4 and for the diffusion Cr-Ti modes: isothermal holding 1 hour at $800^{\circ} \mathrm{C}$, diffusive saturation $\mathrm{Cr}-\mathrm{Ti} 7$ hours. at a temperature of $1100^{\circ} \mathrm{C}$; magnification $600^{x}$

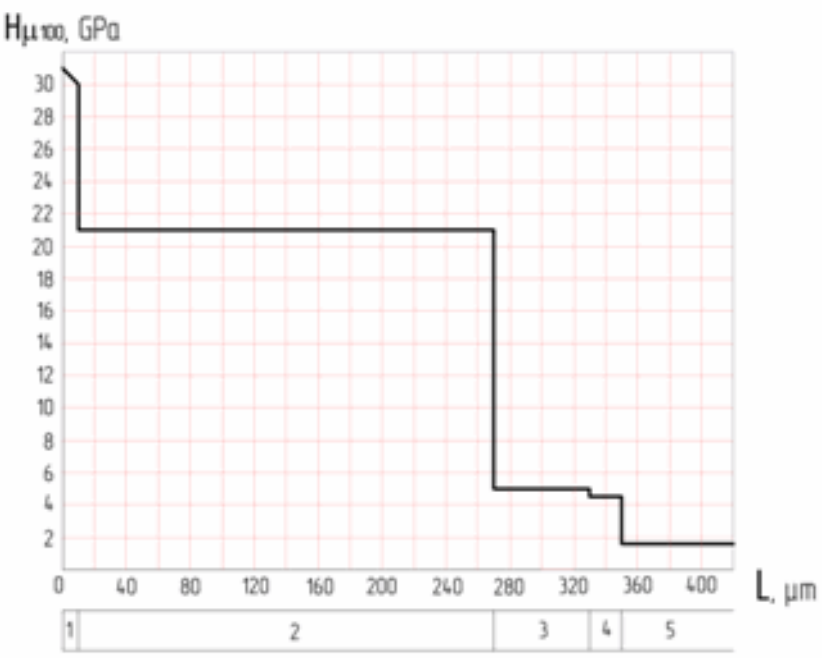

Figure 9. The microhardness averaged diffusion hardened layer of chemically Ni-Co-P coating for recipe №4 and for the diffusion $\mathrm{Cr}-\mathrm{Ti}$ modes: isothermal holding 1 hour at $800^{\circ} \mathrm{C}$, diffusive saturation $\mathrm{Cr}$ - $\mathrm{Ti} 7$ hours at a temperature of $1100^{\circ} \mathrm{C}$

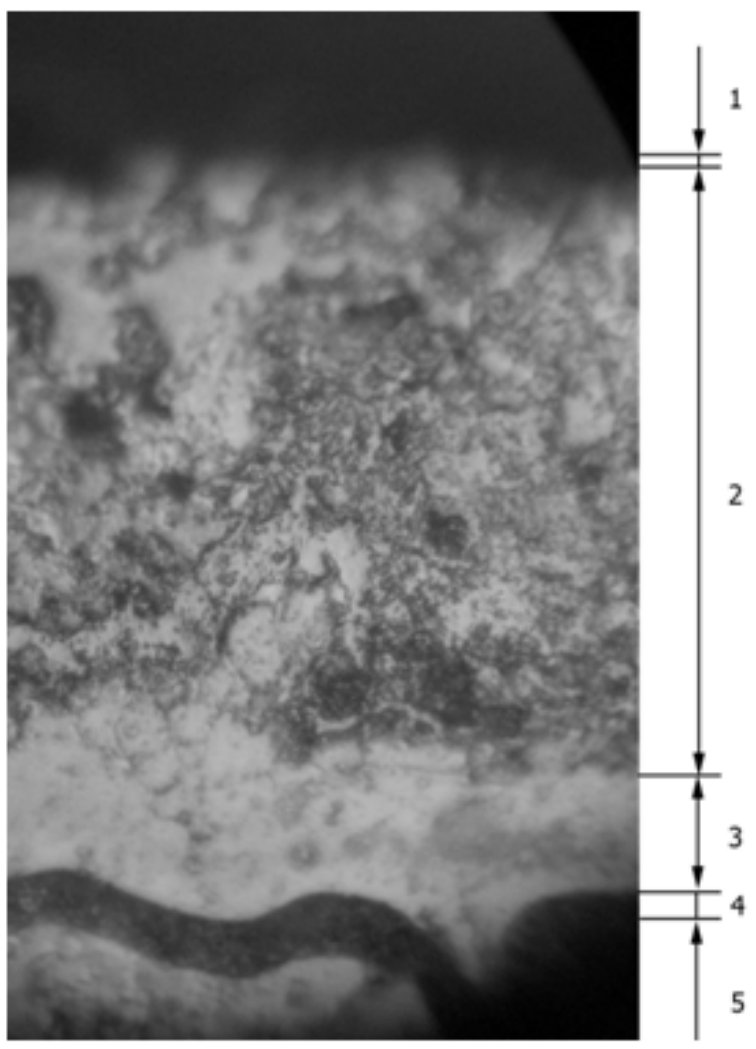

Figure 10. The microstructure of hardened diffusion layer of chemically Ni-Co-P coating for recipe №5 and diffusion Cr-Ti regimes: isothermal holding 1 hour at $800^{\circ} \mathrm{C}$, diffusive saturation $\mathrm{Cr}-\mathrm{Ti} 7$ hours. at a temperature of $1100^{\circ} \mathrm{C}$; magnification $600^{\mathrm{x}}$ 


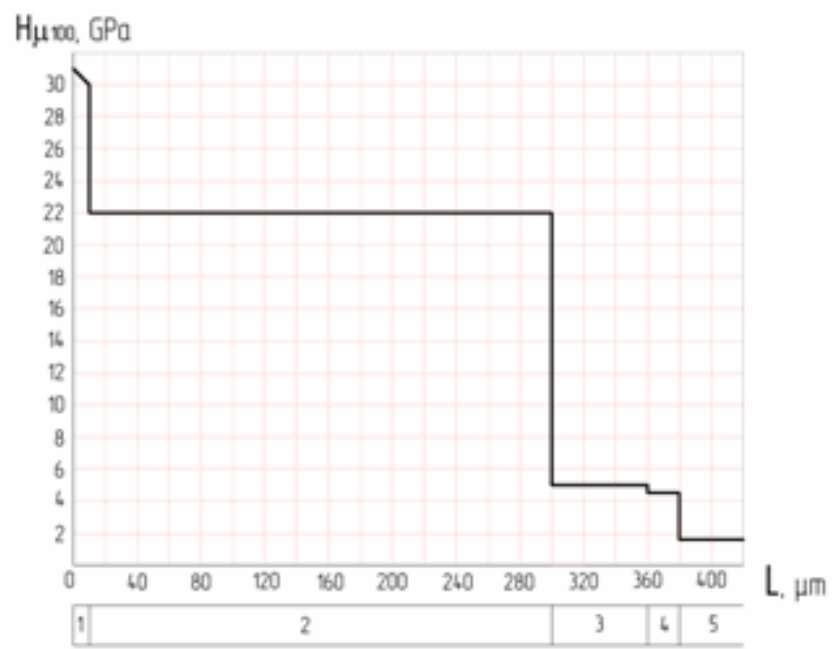

Figure 11. The microhardness averaged diffusion hardened layer of chemically Ni-Co-P coating for recipe №5 and diffusion Cr-Ti regimes: isothermal holding 1 hour at $800^{\circ} \mathrm{C}$, diffusive saturation $\mathrm{Cr}$-Ti 7 hours at a temperature of $1100^{\circ} \mathrm{C}$

To investigate the influence of isothermal holding seven-hour process was conducted on steel diffusion $\mathrm{Cr}-\mathrm{Ti}$ without the use of chemical coatings (Fig. 12). The resulting diffusion layer consists of surface area in titanium carbide microhardness of $35 \mathrm{GPa}$ and a thickness of 10 microns and zone carbides of titanium and chromium microhardness at $25 \mathrm{GPa}$ and a thickness of 100 microns (Figure 13).

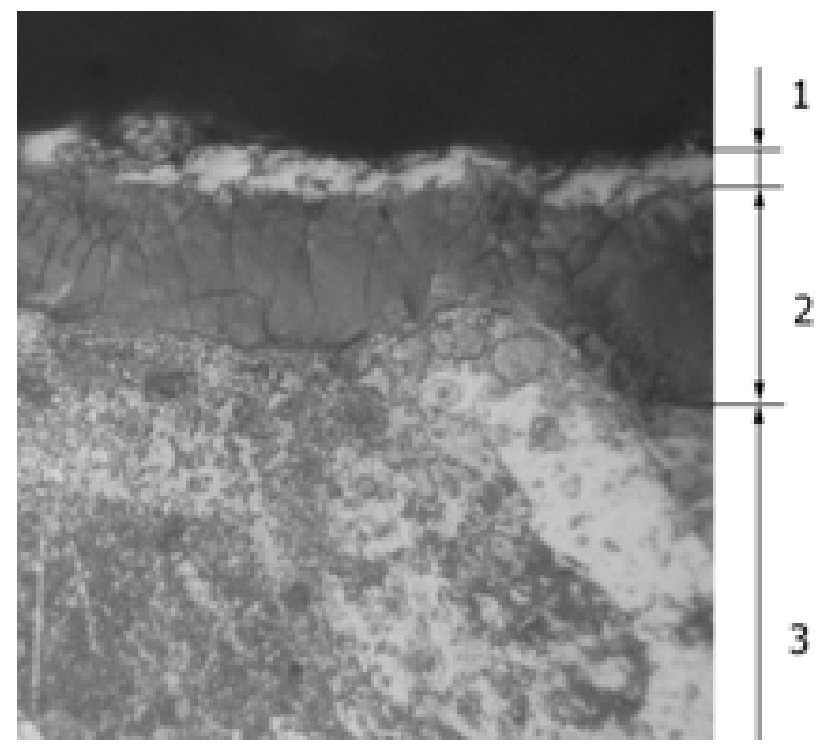

Figure 12. The microstructure of the diffusion hardened diffusion $\mathrm{Cr}-\mathrm{Ti}$ regimes: isothermal holding 1 hour at $800^{\circ} \mathrm{C}$, diffusive saturation $\mathrm{Cr}$ - Ti 7 hours. at a temperature of $1100^{\circ} \mathrm{C}$; magnification $600^{\mathrm{x}}$

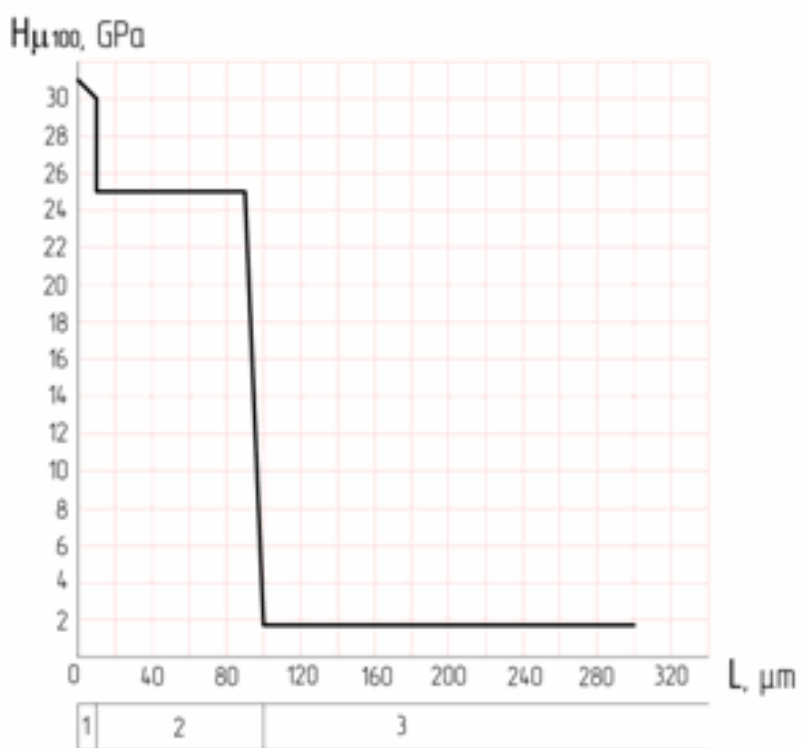

Figure 13. The microhardness averaged diffusion hardened by the diffusion $\mathrm{Cr}$-Ti modes: isothermal holding 1 hour at $800^{\circ} \mathrm{C}$, diffusive saturation $\mathrm{Cr}-\mathrm{Ti} 7$ hours at a temperature of $1100^{\circ} \mathrm{C}$

Morphology of developed diffusion layer composite zone's structure [13], [14] has been obtained after comprehensive restoration steel parts $(0.45 \% \mathrm{C})$ with chemical coating got morphology developed a diffusion layer composite zone structure (Fig. 14). The composite layer 1, a thickness of 250 microns, typical developed network stretched to the physical surface of carbide grains, which are placed in a matrix of a solid solution of chromium in $\alpha$-Fe. On the border of zone 2 , these grains fused into a continuous strand of carbides.

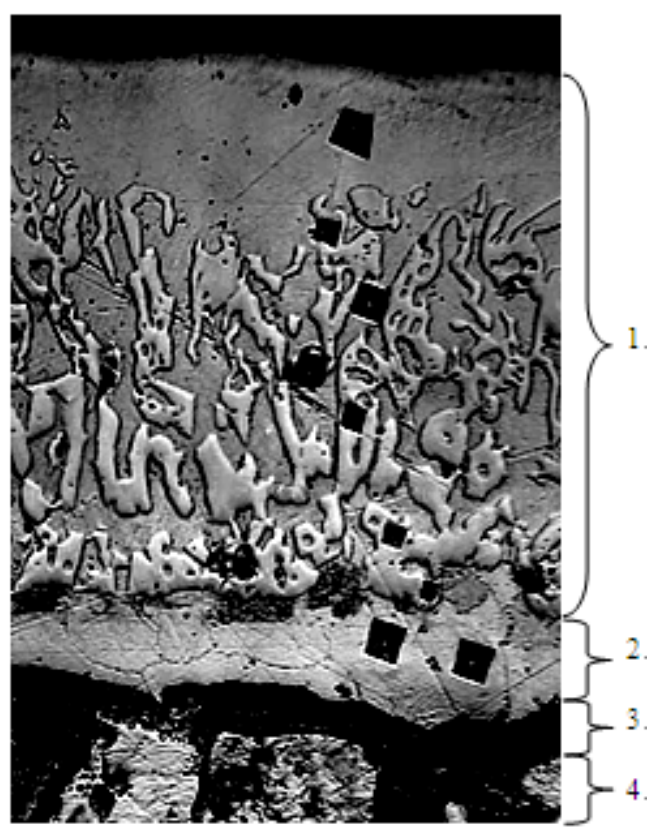

Figure 14. The microstructure of hardened diffusion layer of chemically $\mathrm{Ni}-\mathrm{Co}-\mathrm{P}$ coating and for the diffusion $\mathrm{Cr}$ modes: isothermal holding 1 hour at $800^{\circ} \mathrm{C}$, diffusive saturation $\mathrm{Cr} 7$ hours at a temperature of $1050^{\circ} \mathrm{C}$; magnification $600^{\mathrm{x}}$ 

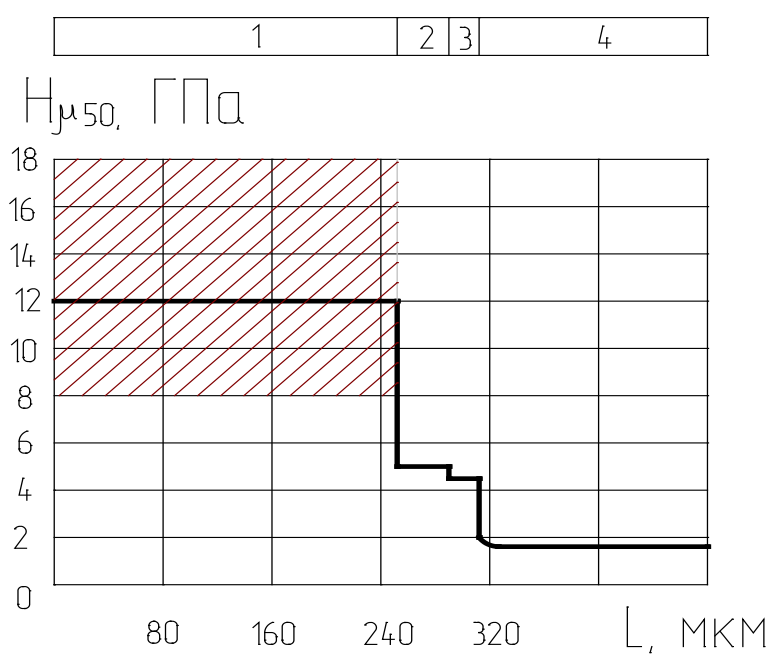

Figure 15. Hardness of hardened diffusion layer of chemically Ni-Co-P coating and for the diffusion $\mathrm{Cr}$ modes: isothermal holding 1 hour at $800^{\circ} \mathrm{C}$, diffusive saturation $\mathrm{Cr} 7$ hours at a temperature of $1050^{\circ} \mathrm{C}$

The carbides grain does not reach the physical surface to 30-50 microns. The integrated composite microhardness zone has $12 \mathrm{GPa}$ (Fig. 15).
Schedule distribution diffusion elements (Fig. 16) confirm that the surface area of a solid solution of chromium in $\alpha \mathrm{Fe}$, in which the diffusion elements of concentration are stable. Peak (above 50\%) of the concentrations of chromium is reached (under falling concentration in these areas of other elements) by depth location carbide grains (Table 1). Zone 2 of homogeneous solid solution of chromium in $\alpha \mathrm{Fe}$ content is characterized by high values of $\mathrm{Ni}(10 \%)$ and $\mathrm{Co}$ (up 3\%). Thickness of Zone 2 is on average 25-40 microns. Obviously, the nickel and other elements pushes carbon from the subsurface zone, and observed the formation of elongated carbide grains, which are located on the border zones 1 and 2 toward physical surface.

The presence of the complex method of chemical treatment and isothermal holding allows reinforcing development at a fairly great depth. Composite Zone 1 with this layer, which in parts friction pairs reaches 250 microns, providing an increased service life.

Phase analysis was performed on this sample twice through a large unidentified peaks, indicated complex state of stress hardened layer. But you can definitely say about the availability of a large number of $\mathrm{Cr}_{7} \mathrm{C}_{3}$ and $\alpha \mathrm{Fe}$.

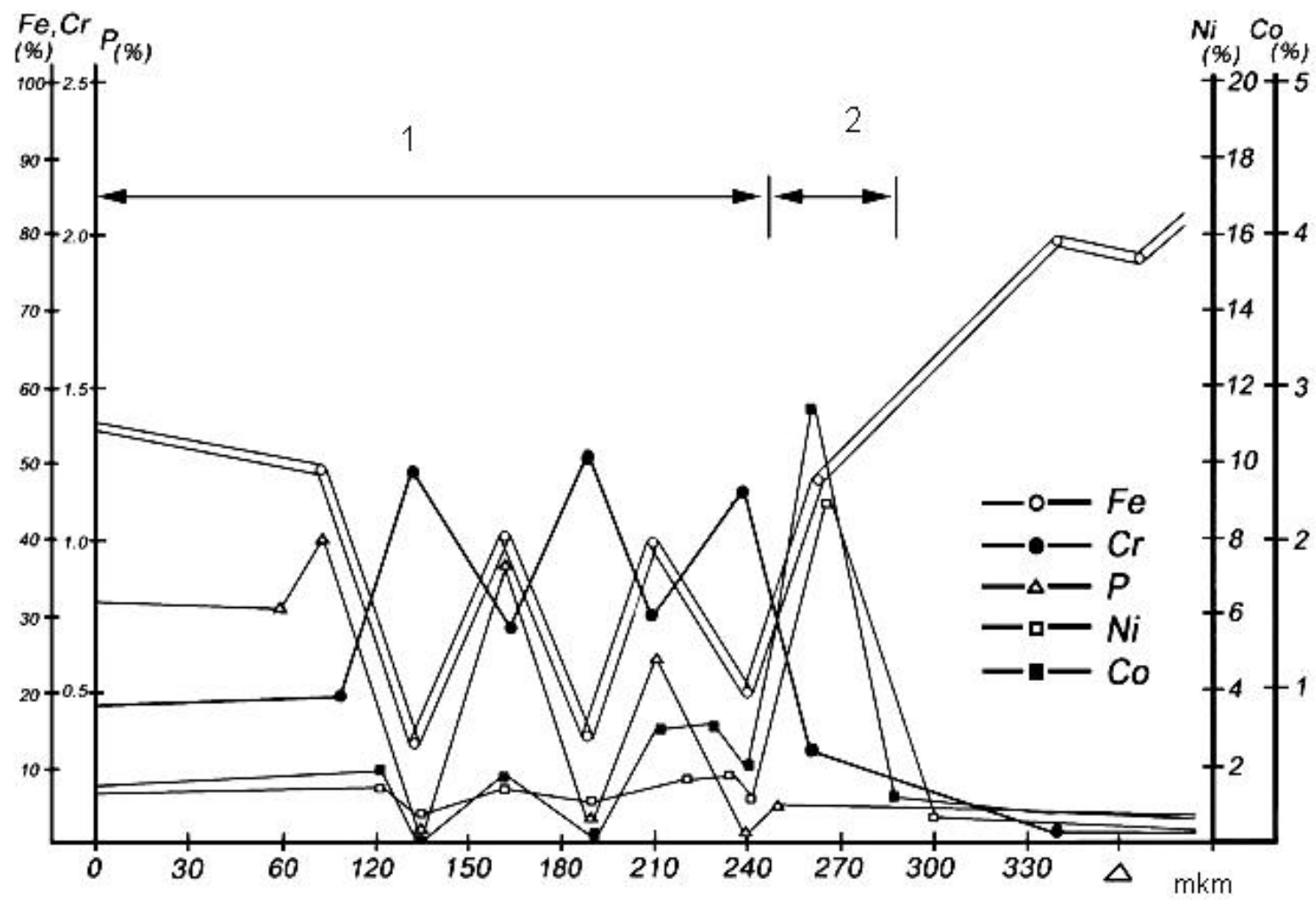

Figure 16. Diffusion concentration distribution of elements diffusion layer of hardened diffusion layer of chemically Ni-Co-P coating and for the diffusion Cr modes: isothermal holding 1 hour at $800^{\circ} \mathrm{C}$, diffusive saturation $\mathrm{Cr} 7$ hours at a temperature of $1050^{\circ} \mathrm{C}$ 


\section{Conclusions}

The complex method includes a surface with chemical vapor deposition developed recipes and thermochemical treatment by accepted modes due to its accessibility and universality. This one enables new qualitative characteristics of surface hardened layers of machine parts, instruments and tools, allowing to expand its scope.

Using a number of new chemical formulations developed to cover certain modes and methods of chemical and thermochemical treatment $\mathrm{Cr}$ - Ti obtained positive results of research to improve the physical and mechanical properties of surfaces iron alloys, namely:

a) considerable thickness diffusion layers (within 200-300 microns of the working area);

b) sufficiently high hardness diffusion layers, which is about 20-25 GPs of working area.

The results of scientific developments set the stage for next advanced and research and their analysis, which will help to develop and to implement practical recommendations for strengthening concrete machinery parts, equipment and tools.

\section{REFERENCES}

[1] S. Lampman, Introduction to Surface Hardening of Steels, Heat Treating, Vol 4, ASM Handbook, ASM International, 1991, p 259-267.

[2] M.Murali1, M.Sambathkumar, M.S.Senthil, Saravanan Micro Structural and Mechanical Properties of AA 7075/Tio2 In Situ Composites, Universal Journal of Materials Science 2(3): 49-53, 2014.

[3] M. Kulka, A. Pertek Characterization of complex $(B+C+N)$ diffusion layers formed on chromium and nickel-based low-carbon steel Original Research Article Applied Surface
Science, Volume 218, Issues 1-4, 30 September 2003, Pages 114-123.

[4] P. Klugkist and Chr. Herzig: Tracer Diffusion schen Wilhelms-Wnive. Tracer Diffusion of Titanium in a-Iron. Physica status solidi (a). Volume 148, Issue 2, 1995. P. 413-421 Article first published online: 17 Feb. 2006. at http://www.readcube.com/articles/10.1002\%2Fpssa.2211480 209?r3_referer=wol\&tracking_action=preview_click\&show checkout $=1 \&$ purchase_referrer=onlinelibrary.wiley.com\&p urchase_site_license=LICENSE_DENIED.

[5] Mulheran, P. A., Nolan, M., Browne, C. S., Basham, M., Sanville, E. and Bennett, R. A. (2010) Surface and interstitial $\mathrm{Ti}$ diffusion at the rutile $\mathrm{TiO} 2$ (110) surface. Physical Chemistry Chemical Physics, 12 (33). pp. 9763-9771. ISSN 1463-9076 doi: 10.1039/C002698K Available at http://centaur.reading.ac.uk/5776/.

[6] Cui, Y.W.; Hu, Rui; Li, Weibang; Tang, Bin; Zhou, Lian Al-Cr-Ti Assessment of diffusion mobility for the bcc phase (2013-04-01) at http://hdl.handle.net/11115/94.

[7] Wang, H.; Warnken, N.; Reed, R.C. Al-Cr-Ti-V Thermodynamic assessment of the ordered B2 phase (2013-03-29) at http://hdl.handle.net/11115/84.

[8] UA 110115, C23C 22/63, C23C 22/52, C23C 22/03; 25.11.2015.

[9] UA 97337, C23C 22/14, C23C 22/22, C23C 22/63; 25.01.2012.

[10] UA 97335, C23C 22/14, C23C 22/22, C23C 22/63; 25.01.2012.

[11] UA 97333, C23C 22/14, C23C 22/22, C23C 22/63; 25.01.2012.

[12] UA 110080, C23C 10/02, C23C 10/18, C23C 10/26, C23C $22 / 02 ; 10.11 .2015$.

[13] UA 109285, C23C 10/32, C23C 22/62, C23C 22/05, C23C $10 / 02 ; 10.08 .2015$.

[14] UA 110046, C23C 10/02, C23C 10/40, C23C 10/32, C23C $22 / 02 ; 10.11 .2015$. 